\title{
A review of Neogene and Quaternary pikes of southeastern Europe and a new species from the early Pleistocene of Nogaisk, Ukraine
}

Oleksandr M. Kovalchuk, Mark V.H. Wilson, and Terry Grande

Acta Palaeontologica Polonica 62 (1), 2017: 121-135 doi:https://doi.org/10.4202/app.00311.2016

The fish genus Esox (Teleostei, Esocidae) has been recorded from thirty late Miocene, Pliocene, and Pleistocene localities where forty-one bone-bearing strata are exposed in the territory of Ukraine, Russian Federation, and Republic of Moldova. From eight localities the genus is reported or described for the first time. A detailed description and morphological analysis of the currently available osteological material demonstrates the presence of four species in the studied area: (i) Esox sibiricus (late Miocene-early Pliocene); (ii) Esox moldavicus (early Pliocene-early Pleistocene); (iii) Esox nogaicus sp. nov. (early Pleistocene, Calabrian); (iv) Esox lucius (early-middle Pleistocene). The Northern Pike (Esox lucius) is recorded for the first time in the early Pleistocene fossil record of southeastern Europe. The new species E. nogaicus is characterized by a massive dentary with deep symphysis and the possible presence of a pair of fixed canine-like teeth near the anterior end of the vomer. Such canine teeth are seen also in certain species known only from North America, the extant Esox masquinongy, the fossil species E. columbianus, and an unnamed Miocene form. However, unlike in E. nogaicus, in the three North American species fixed canines also occur anteriorly on the palatines. The Miocene, Pliocene, and Pleistocene pikes from southeastern Europe document a greater diversity of morphologies in the past than exists today in the pike species of Europe. Changes in the predominant species of Esox in southeastern Europe are hypothesized to be driven by changing global and regional climates.

Key words: Esociformes, Esocidae, Esox, Miocene, Pliocene, Pleistocene, Ukraine, Russia, Moldova.

Oleksandr M. Kovalchuk [biologiest@ukr.net], Department of Paleontology, National Museum of Natural History at the National Academy of Sciences of Ukraine, 15 Bogdan Khmelnitsky str., Kyiv 01601 Ukraine. Mark V.H. Wilson [mvwilson@ualberta.ca ], Department of Biological Sciences, University of Alberta, Edmonton, Alberta T6G 2E9, Canada. Terry Grande [tgrande@luc.edu], Department of Biology, Loyola University Chicago, Chicago, Illinois 60660, USA. 
This is an open-access article distributed under the terms of the Creative Commons

Attribution License (for details please see creativecommons.org), which permits unrestricted use, distribution, and reproduction in any medium, provided the original author and source are credited.

FoF 